\title{
A multistage AC-AC converter designed by using switched capacitor techniques
}

\author{
Kei Eguchi ${ }^{1, *}$, Wanglok Do ${ }^{1}$, Soranut Kittipanyangam ${ }^{1}$, Kanji Abe ${ }^{1}$, Ichirou Oota ${ }^{2}$ \\ ${ }^{1}$ Department of Information Electronics, Fukuoka Institute of Technology, Fukuoka, Japan \\ ${ }^{2}$ Department of Information, Communication and Electronic Engineering, National Institute of Technology, Kumamoto College, \\ Kumamoto, Japan
}

\section{A R T I C LE IN F O}

\section{Article history:}

Received 16 February 2017

Received in revised form

1 September 2017

Accepted 20 September 2017

Keywords:

Multistage converters

AC-AC converters

Switched-capacitor circuits

Step-up/step-down converters

\begin{abstract}
A B S T R A C T
To realize small and light ac-ac converter, a switched-capacitor (SC) technique is one of the most promising techniques, because heavy core and windings are not necessary to design the SC ac-ac converter. In this paper, a multistage direct ac-ac converter is designed by using SC techniques. Unlike conventional SC ac-ac converters, the proposed SC ac-ac converter consists of $N(=2,3, \ldots)$ converter blocks with symmetrical converter topology. To achieve high step-up/step-down gain, an input ac voltage is converted several times by the series-connected converter blocks. Due to the symmetrical multistage topology, the proposed SC ac-ac converter achieves not only high step-up/step-down gain but also fewer capacitors than conventional SC ac-ac converters. In other words, the proposed ac-ac converter can improve power efficiency and input power factor from conventional SC ac-ac converters. To clarify the characteristics of the proposed SC ac-ac converter, operation principle, qualitative analysis and simulation evaluation are presented. The validity of circuit design is confirmed by simulation program with integrated circuit emphasis (SPICE) simulations.
\end{abstract}

(C) 2017 The Authors. Published by IASE. This is an open access article under the CC BY-NC-ND license (http://creativecommons.org/licenses/by-nc-nd/4.0/).

\section{Introduction}

To offer stepped-up / stepped-down voltages to a load, a transformer is one of the most popular solutions. Among others, unlike a voltage transformer which has two isolated windings, an autotransformer has the usual magnetic core but only has one winding. Therefore, no interference or disturbance isolation can be offered by the autotransformer. However, due to the magnetic core and winding, the autotransformer is heavy and bulky. Moreover, the auto-transformer is difficult to achieve high power efficiency because of core losses and copper losses. To solve these problems, a direct ac-ac converter has been designed by using switched capacitor (SC) techniques. Due to the inductor-less topology, the SC ac-ac converter can realize light weight, small size, no flux of magnetic induction, and so on.

To light an electroluminescent lamp, the first SC ac-ac converter was proposed by Ueno et al. (1993).

\footnotetext{
* Corresponding Author.

Email Address: eguti@fit.ac.jp (K. Eguchi)

https://doi.org/10.21833/ijaas.2017.012.015

2313-626X/@ 2017 The Authors. Published by IASE.

This is an open access article under the CC BY-NC-ND license

(http://creativecommons.org/licenses/by-nc-nd/4.0/)
}

In the first ac-ac SC converter, a modified sinusoidal waveform is generated by boosting an input ac voltage. Following this study, in order to enhance the flexibility of conversion ratios, a ring-type SC ac-ac converter was suggested by Terada et al. (2004) and Eguchi et al. (2009). Unlike the first SC ac-ac converter, the ring-type SC ac-ac converter can create an arbitrary output waveform by changing the number of series-connected capacitors. However, the circuit topology of the ring-type ac-ac converter is complex. To simplify the circuit topology, Lazzarin et al. $(2012,2013)$ and Andersen et al. (2013) designed a direct SC ac-ac converter. By connecting a flying capacitor to charge-transfer capacitors alternately, the direct ac-ac converter can achieve not only $1 / 2 x$ step-down conversion but also $2 \mathrm{x}$ step-up conversion. Following this study, You and Hui (2014) expanded Lazzarin's ac-ac converter to realize the ratio of $1 / 4$. However, the direct ac-ac converter reported in (Lazzarin et al., 2012; 2013; Andersen et al., 2013; You and Hui, 2014) is difficult to achieve high step-up/step-down gain though these conventional converters have simple converter topology. In other words, there is still room for improvement in the converter topology of the conventional SC ac-ac converters. In this paper, a multistage direct SC ac-ac converter is designed by 
using SC techniques. Unlike the conventional SC acac converters, the proposed ac-ac converter consists of $N(=2,3, \ldots)$ converter blocks with symmetrical converter topology. To achieve high step-up/stepdown gain, the input ac voltage is converted several times by the series-connected converter blocks. Due to the symmetrical multistage topology, the proposed SC ac-ac converter achieves not only high step-up/step-down gain but also fewer capacitors than the conventional SC ac-ac converters. In other words, the proposed ac-ac converter can improve power efficiency and input power factor from the conventional SC ac-ac converters. To demonstrate the effectiveness of the proposed ac-ac converter, simulation program with integrated circuit emphasis (SPICE) simulations and theoretical analysis are performed.

The rest of this paper is organized as follows. First, the circuit configuration of the conventional SC ac-ac converters is presented to demonstrate the features of the SC ac-ac converter. Next, the circuit configuration of the proposed ac-ac converter is shown. Then, the characteristic of the proposed ac-ac converter is clarified theoretically. After that, the validity of circuit design of the proposed ac-ac converter is confirmed by SPICE simulation. Finally, conclusion and future work are drawn.

\section{Conventional SC AC-AC converter}

Fig. 1 illustrates the circuit configuration of the conventional SC ac-ac- converter proposed by Andersen et al. (2013) and You and Hui (2014). The conventional ac-ac converter consists of $2 M-1(=2,3$, $4, \ldots)$ capacitors and $2 M$ switches. The converter topology of Fig. 1 is based on the SC dc-dc converter proposed by Hara et al. (1997). As you can see from Fig. 1, the conventional ac-ac converter consists of 8 bidirectional switches and 7 capacitors, where bidirectional switches $S_{1}$ and $S_{2}$ are driven by nonoverlapped two phase clock pulses with constant switching frequency and duty cycle. In Fig. 1, the input ac voltage is divided by main capacitors $C_{4}, C_{5}$, $C_{6}$, and $C_{7}$. By changing the connection of flying capacitors $C_{1}, C_{2}$, and $C_{3}$, the voltages of $C_{4}, C_{5}, C_{6}$, and $C_{7}$ are averaged. Therefore, the conventional converter achieves the $1 / 4 \mathrm{x}$ step-down conversion. of course, by swapping the input and output terminals, the conventional converter can achieve the $4 \mathrm{x}$ step-up conversion. However, due to the flying capacitors, the conventional converter is difficult to achieve high power efficiency and high input power factor. Furthermore, according to the step-up/step-down gain of the conventional ac-ac converter, the number of capacitors increases linearly.

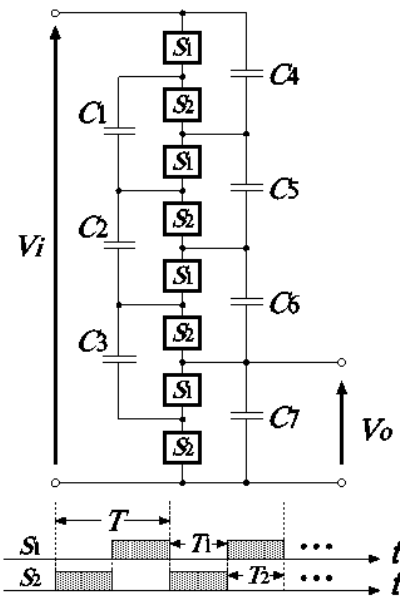

Fig. 1: Conventional SC a-ac converter

\section{Proposed SC AC-AC converter}

Fig. 2 illustrates the circuit configuration of the proposed SC ac-ac converter. Unlike the conventional ac-ac converter, the proposed ac-ac converter consists of series-connected $N(=2,3, \ldots)$ converter blocks with symmetrical converter topology, where the converter block has no flying capacitors. Furthermore, by converting the input ac voltage several times, the proposed converter can achieve high step-up/step-down gain with small number of capacitors. By controlling bidirectional switches, the proposed converter realizes the following conversion ratios:

$\frac{v_{\text {out }}}{v_{\text {in }}}=\prod_{i=1}^{N} m_{i}$,

where $m_{i}$ is the step-up/step-down gain of a converter block. Fig. 3 demonstrates an example of the proposed ac-ac converter in the case of the $1 / 4 \mathrm{x}$ conversion. As you can see from Figs. 1-3, the number of capacitors for the proposed converter is smaller than that for the conventional converter though the circuit configuration of the proposed converter is complex.

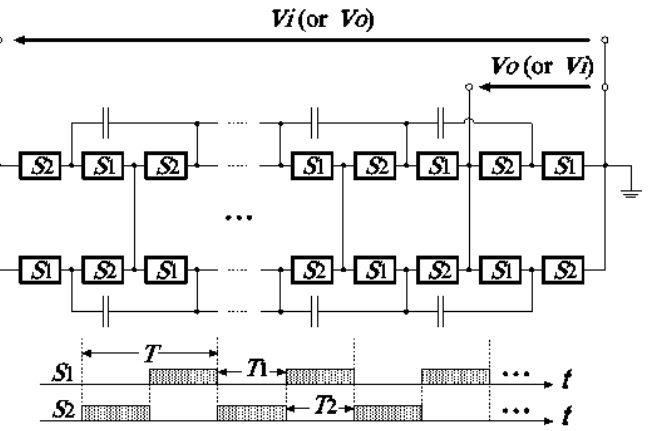

(b)

Fig. 2: Proposed SC a-ac converter; (a) block diagram and (b) converter block 


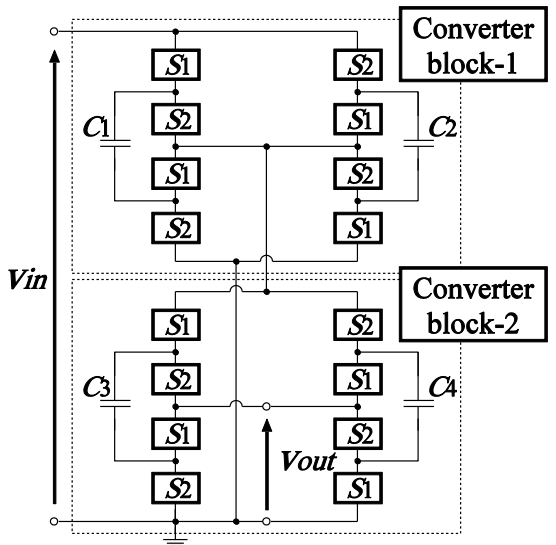

Fig. 3: Proposed converter in the case of the $1 / 4 \mathrm{x}$ conversion

Fig. 4 shows the instantaneous equivalent circuits of Fig. 3 in the case of the $1 / 4 \mathrm{x}$ step-down conversion, where the bidirectional switch is modeled by an ideal lossless switch and an onresistance $R_{o n}$. By changing the connection order of $\left(C_{1}, C_{3}\right)$ and $\left(C_{2}, C_{4}\right)$, the proposed converter performs voltage conversion. Therefore, unlike the conventional converter of Fig. 1, the number of capacitors connected to the $\mathrm{I} / \mathrm{O}$ terminals is constant.

\section{Theoretical analysis}

As an example of the proposed ac-ac converter, the characteristics of the $1 / 4 \mathrm{x}$ step-down converter shown in Fig. 3 are analyzed theoretically. In the theoretical analysis, the ac input is assumed as a pulse ac waveform to estimate the maximum power efficiency and the maximum output voltage. If the input is the ac waveform, the SC ac-ac converter can be analyzed by using a four-terminal equivalent circuit (Eguchi et al., 2010) shown in Fig. 5, because the SC ac-ac converter behaves like a dc-dc converter. In Fig. 5, $R_{s c}$ is the SC resistance and $R$ is the conversion ratio of an ideal transformer. These parameters are derived by utilizing instantaneous equivalent circuits of Fig. 4.

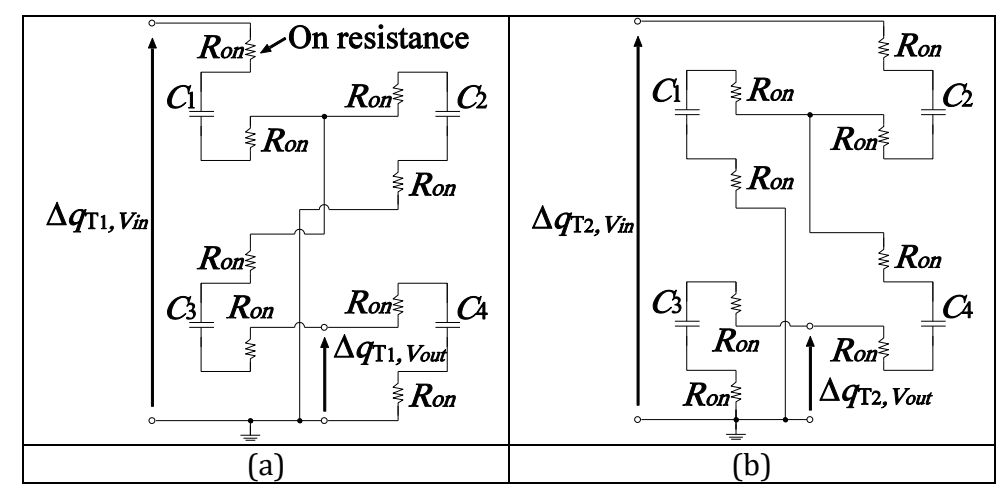

Fig. 4: Proposed SC a-ac converter; (a) block diagram and (b) converter block

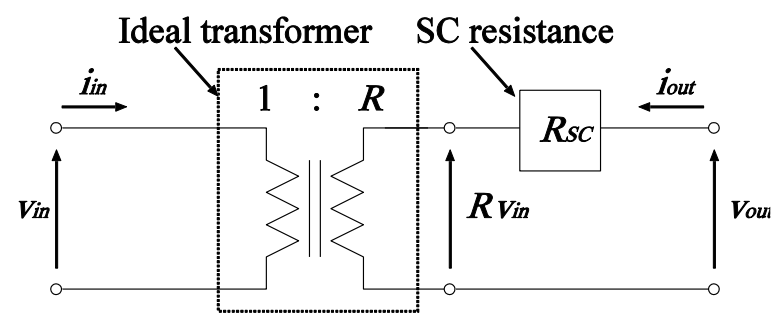

Fig. 5: Proposed converter in the case of the $1 / 4 \mathrm{x}$ conversion

In steady state, the differential value of electric charges $\Delta q_{T i}^{k}$ in $C_{k}(k=1, \ldots, 4)$ satisfies

$\Delta q_{T_{1}}^{k}+\Delta q_{T_{2}}^{k}=0$

where $\Delta q_{T i}^{k}(i=1,2)$ denotes the electric charge of the $k$-th capacitor in State- $T_{i}$. The interval of State- $T_{i}$ satisfies

$T=T_{1}+T_{2}$ and $T_{1}=T_{2}=\frac{T}{2}$

where $T$ is a period of the clock pulse and $T_{i}$ is the interval of State- $T_{i}$.

In State- $T_{1}$, the differential values of electric charges in the input and the output, $\Delta q_{T 1, v i n}$ and $\Delta q_{T 1, \text { vout }}$, are expressed as
$\Delta q_{T_{1}, v_{i n}}=\Delta q_{T_{1}}^{1}$,

$\Delta q_{T_{1}, v_{\text {out }}}=-\Delta q_{T_{1}}^{3}+\Delta q_{T_{1}}^{4}$

$\Delta q_{T_{1}}^{1}=\Delta q_{T_{1}}^{2}+\Delta q_{T_{1}}^{3}$.

On the other hand, in State- $T_{2}$, the differential values of electric charges in the input and the output, $\Delta q_{T 2, v i n}$ and $\Delta q_{T 2, v o u t}$, are expressed as

$\Delta q_{T_{2}, v_{i n}}=\Delta q_{T_{2}}^{2}$

$\Delta q_{T_{2}, v_{\text {out }}}=\Delta q_{T_{2}}^{3}-\Delta q_{T_{2}}^{4}$

$\Delta q_{T_{2}}^{2}=\Delta q_{T_{2}}^{1}+\Delta q_{T_{2}}^{4}$.

Here, since the proposed ac-ac converter has symmetrical topology, the following conditions are satisfied:

$\Delta q_{T_{1}}^{1}=\Delta q_{T_{2}}^{2}$

$\Delta q_{T_{1}}^{2}=\Delta q_{T_{2}}^{1}$

$\Delta q_{T_{1}}^{3}=\Delta q_{T_{2}}^{4}$

$$
\Delta q_{T_{1}}^{4}=\Delta q_{T_{2}}^{3}
$$

Using (4) and (5), the I/O currents, $i_{\text {in }}$ and $i_{\text {out }}$, can be expressed as

$i_{\text {in }}=\frac{\Delta q_{v_{\text {in }}}}{T}=\frac{\Delta q_{T_{1}, v_{i n}}+\Delta q_{T_{2}, v_{\text {in }}}}{T}$

$i_{\text {out }}=\frac{\Delta q_{v_{\text {out }}}}{T}=\frac{\Delta q_{T_{1}, v_{\text {out }}}+\Delta q_{T_{2}, v_{\text {out }}}}{T}$, 
because the overall change of I/O currents is zero in steady state. In (7), $\Delta q_{\text {vin }}$ and $\Delta q_{\text {vout }}$ are electric charges in $v_{\text {in }}$ and $v_{\text {out }}$, respectively. Substituting (2) (6) into (7), we have the relation between the input current and the output current as follows:

$i_{\text {in }}=-\frac{1}{4} i_{\text {out }}$,

where

$\Delta q_{v_{\text {in }}}=-\frac{1}{4} \Delta q_{v_{\text {out }}}$

Therefore, the conversion ratio in Fig. 5 can be obtained as $R=1 / 4$.

Next, in order to derive the SC resistance $R_{S C}$, the consumed energy in one period is discussed by using the instantaneous equivalent circuits of Fig. 4. In Fig. $4 \mathrm{a}$, the consumed energy $W_{T 1}$ is expressed as

$W_{T_{1}}=\frac{\left(\Delta q_{T_{1}}^{1}\right)^{2}}{T_{1}} 2 R_{o n}+\frac{\left(\Delta q_{T_{1}}^{2}\right)^{2}}{T_{1}} 2 R_{o n}+\frac{\left(\Delta q_{T_{1}}^{3}\right)^{2}}{T_{1}} 2 R_{o n}+$

$\frac{\left(\Delta q_{T_{1}}^{4}\right)^{2}}{T_{1}} 2 R_{o n}$.

Using (2) - (6), the consumed energy (9) can be rewritten as

$W_{T_{1}}=\left(\frac{5 R_{\text {on }}}{8}\right) \frac{\left(\Delta q_{v_{\text {out }}}\right)^{2}}{T}$

Therefore, the total consumed energy in one period can be obtained as

$W_{T}=2 W_{T_{1}}=\left(\frac{5 R_{\text {on }}}{4}\right) \frac{\left(\Delta q_{v_{\text {out }}}\right)^{2}}{T}$

because the proposed ac-ac converter has symmetrical topology. On the other hand, the consumed energy of Fig. 5 is expressed as

$W_{T}=R_{S C} \frac{\left(\Delta q_{v_{\text {out }}}\right)^{2}}{T}$

From (11) and (12), we have the SC resistance $R_{S C}$ as

$R_{S C}=\frac{5}{4} R_{\text {on }}$

Finally, by combining (8) and (13), the equivalent circuit is derived as

$\left[\begin{array}{l}v_{\text {in }} \\ i_{\text {in }}\end{array}\right]=\left[\begin{array}{cc}4 & 0 \\ 0 & 1 / 4\end{array}\right]\left[\begin{array}{cc}1 & (5 / 4) R_{\text {on }} \\ 0 & 1\end{array}\right]\left[\begin{array}{c}v_{\text {out }} \\ -i_{\text {out }}\end{array}\right]$

because it is known that the four-terminal equivalent circuit of Fig. 5 can be expressed by the K-matrix. From (14), we have the maximum efficiency and the maximum output voltage as

$$
\begin{aligned}
& \eta_{\text {max }}=\frac{R_{L}}{(5 / 4) R_{o n}+R_{L}} R_{o n} \\
& v_{\text {out.max }}=\left\{\frac{R_{L}}{(5 / 4) R_{o n}+R_{L}}\right\}\left(\frac{v_{i n}}{4}\right)
\end{aligned}
$$

Of course, the characteristics of the step-up mode can be analyzed by the same method.
Table 1 shows the comparison of SC resistances between the proposed converter and the conventional converter in conversion ratios of $1 / 4$ and 4 . As you can see from Table 1 , the proposed acac converter can achieve not only fewer number of capacitors but also smaller SC resistance than the conventional ac-ac converter. In other words, the proposed ac-ac converter can achieve higher power efficiency than the conventional ac-ac converter.

Table 1: Comparison of SC resistances

\begin{tabular}{ccc}
\hline & \multicolumn{2}{c}{ Conversion ratio } \\
\cline { 2 - 3 } & $1 / 4 \mathrm{x}$ & $4 \mathrm{x}$ \\
\hline Proposed converter & $(5 / 4) R_{o n}$ & $20 R_{o n}$ \\
Conventional converter & $3 R_{o n}$ & $48 R_{o n}$ \\
\hline
\end{tabular}

\section{Simulations}

To clarify the characteristics of the proposed acac converter, SPICE simulations are performed concerning the proposed ac-ac converter shown in Fig. 3. Furthermore, the characteristics of the proposed converter are compared with that of the conventional ac-ac converter shown in Fig. 1. The SPICE simulations are performed under conditions that $v_{\text {in }}=220 \mathrm{~V} @ 50 \mathrm{~Hz}, C_{1}=\ldots=C_{4}=33 \mu \mathrm{F}, C_{\text {out }}=1 \mathrm{nF}$, $R_{\text {on }}=0.83 \Omega, T=10 \mu \mathrm{s}$, and $T_{1}=T_{2}=5 \mu \mathrm{s}$, where $C_{\text {out }}$ denotes the output capacitance of the ac-ac converter.

Fig. 6 demonstrates the simulated output voltages of the proposed ac-ac converter. As Fig. 6 shows, the proposed ac-ac converter can offer not only a stepped-down voltage but also a stepped-up voltage. Concretely, in Fig. 6, about 55V@50Hz and $880 @ 50 \mathrm{~Hz}$ outputs are obtained by converting the $220 @ 50 \mathrm{~Hz}$ input.

Fig. 7 demonstrates the simulated power efficiency as a function of the output power. As Fig. 7 shows, the power efficiency of the proposed ac-ac converter is higher than that of the conventional acac converter. Concretely, in the case of the $1 / 4 x$ stepdown conversion, the proposed AC-AC converter can improve power efficiency more than $17 \%$ when the output power is $0.25 \mathrm{~kW}$. In a range from $0.03 \mathrm{~kW}$ to $0.44 \mathrm{~kW}$, the proposed ac-ac converter can achieve more than $80 \%$ efficiency. On the other hand, in the case of the $4 \mathrm{x}$ step-up conversion, the proposed ac-ac converter can improve power efficiency more than $16 \%$ when the output power is $4 \mathrm{~kW}$. In a range from $3 \mathrm{~kW}$ to $5.6 \mathrm{~kW}$, the proposed ac-ac converter can achieve more than $80 \%$ efficiency. Of course, the power efficiency of ac-ac converters depends on the on-resistance of bidirectional switches, clock frequency, capacity values, and so on.

Fig. 8 demonstrates the input power factor as a function of the output power. As Fig. 8 shows, the input power factor of the proposed ac-ac converter is higher than that of the conventional ac-ac converter. Concretely, in the case of the $1 / 4 \mathrm{x}$ step-down conversion, the proposed ac-ac converter can improve power factor more than 0.34 when the output power is $0.25 \mathrm{~kW}$. The input power factor of the proposed ac-ac converter is more than 0.8 when 
the output power is higher than $0.36 \mathrm{~kW}$. On the other hand, in the case of the $4 \mathrm{x}$ step-up conversion, the input power factor of the proposed ac-ac converter is almost the same as that of the

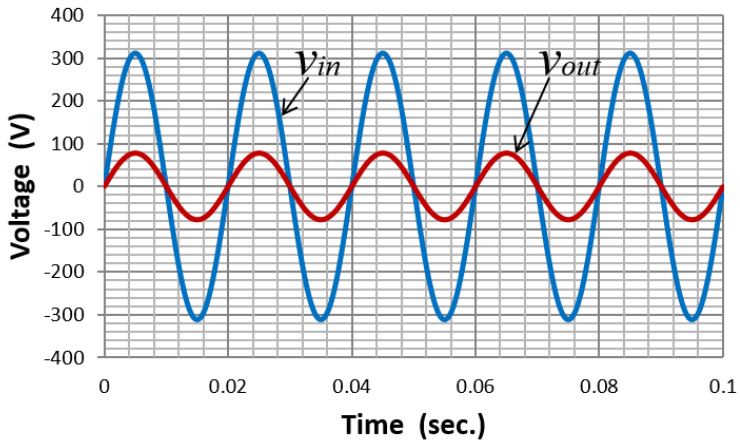

(a) conventional ac-ac converter when the output power is $4 \mathrm{~kW}$. The input power factor of the proposed ac-ac converter is more than 0.8 when the output power is higher than $4.4 \mathrm{~kW}$.

Fig. 6: Simulated output voltage (a) 1/4x step-down conversion and (b) 4x step-up conversion

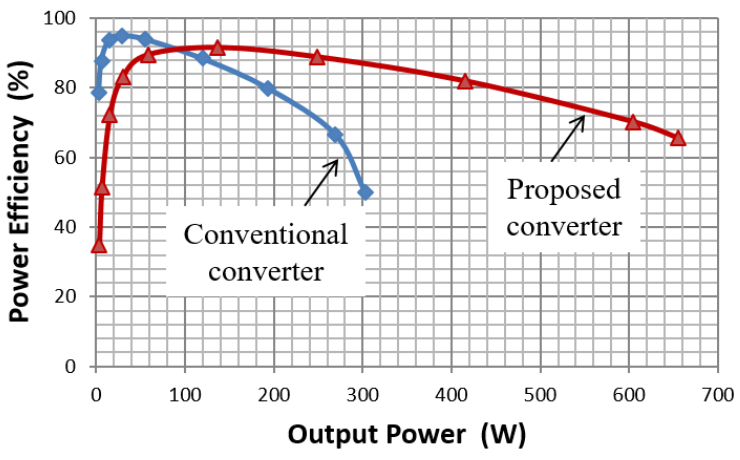

(a)

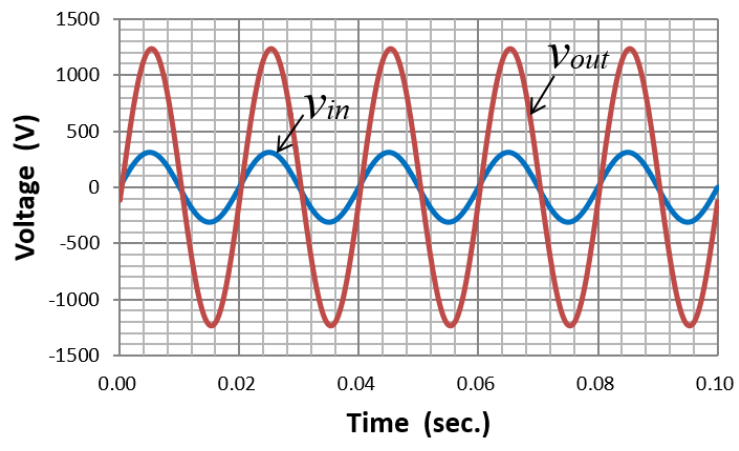

(b)

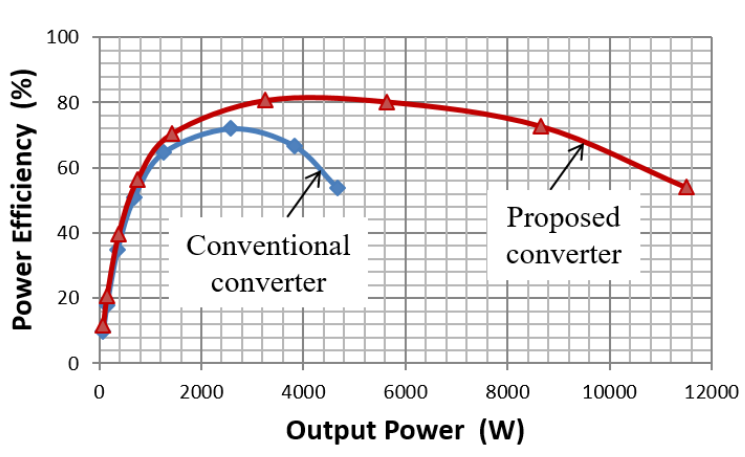

(b)

Fig. 7: Simulated power efficiency as a function of the output power (a) 1/4x step-down conversion and (b) 4x step-up conversion

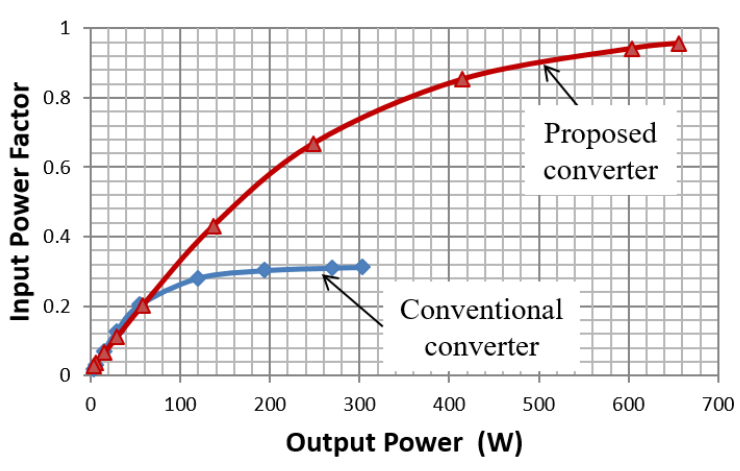

(a)

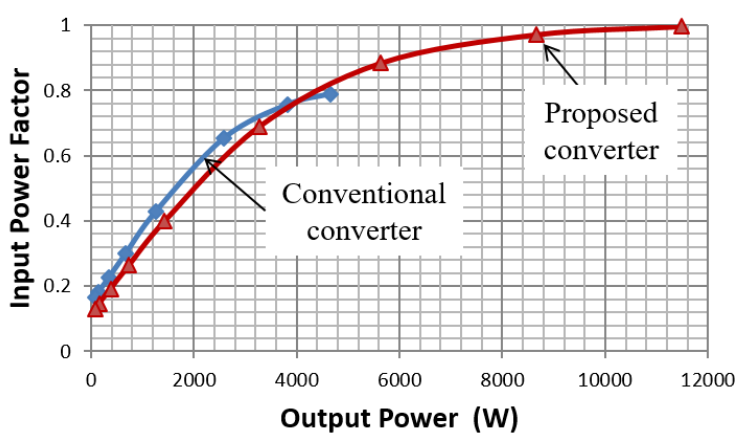

(b)

Fig. 8: Simulated input power factor as a function of the output power (a) 1/4x step-down conversion and (b) 4x step-up conversion

\section{Conclusion}

A multistage direct SC ac-ac converter has been proposed in this paper. Due to the symmetrical multistage topology, the proposed SC ac-ac converter achieves not only high step-up/step-down gain but also fewer capacitors than the conventional SC ac-ac converters. Concerning the simplest proposed ac-ac converter realizing the $1 / 4 \mathrm{x}$ and $4 \mathrm{x}$ conversion ratios, the validity of circuit design was confirmed by SPICE simulations. The SPICE simulation demonstrated the following results:
1. By swapping the input and output terminals, the proposed ac-ac converter can offer not only a stepped-down voltage but also a stepped-up voltage. Concretely, about 55V@50Hz and $880 @ 50 \mathrm{~Hz}$ outputs were obtained by converting the 220@50Hz input.

2. The proposed ac-ac converter can achieve higher power efficiency than the conventional ac-ac converter. Concretely, in the case of the $1 / 4 x$ stepdown conversion, the proposed ac-ac converter improved power efficiency more than 17\% from the conventional ac-ac converter when the output 
power is $0.25 \mathrm{~kW}$. On the other hand, in the case of the $4 \mathrm{x}$ step-up conversion, the proposed ac-ac converter improved power efficiency more than $16 \%$ when the output power is $4 \mathrm{~kW}$.

3. The proposed ac-ac converter can achieve higher input power factor than the conventional ac-ac converter. Concretely, in the case of the $1 / 4 \mathrm{x}$ stepdown conversion, the proposed ac-ac converter improved input power factor more than 0.34 when the output power is $0.25 \mathrm{~kW}$. On the other hand, in the case of the $4 \mathrm{x}$ step-down conversion, the input power factor of the proposed ac-ac converter was almost the same as that of the conventional ac-ac converter when the output power is $4 \mathrm{~kW}$.

The experiment concerning the proposed ac-ac converter is left to a future study.

\section{References}

Andersen RL, Lazzarin TB, and Barbi I (2013). A 1-kW stepup/step-down switched-capacitor AC-AC converter. IEEE Transactions on Power Electronics, 28(7): 3329-3340.

Eguchi K, Oota I, Terada S, and Inoue T (2009). A design method of switched-capacitor power converters by employing a ringtype power converter. International Journal of Innovative Computing, Information and Control, 5(10A): 2927-2938.

Eguchi K, Pongswatd S, Tirasesth K, Sasaki H, and Inoue T (2010). Optimal design of a single-input parallel DC-DC converter designed by switched capacitor techniques. International Journal of Innovative Computing, Information and Control, 6(1A): 215-227.

Hara N, Oota I, and Ueno F (1997). A continuous current switchedcapacitor DC-DC converter with fixed-capacitors and a voltage averaging capacitor. In the International Conference on Nonlinear Theory and its Applications (NOLTA'97), 2: 12091212. Available online at: http://ci.nii.ac.jp/naid/ 10007983995/

Lazzarin TB, Andersen RL, Martins GB, and Barbi I (2012). A 600 W switched-capacitor AC-AC converter for $220 \mathrm{~V} / 110 \mathrm{~V}$ and $110 \mathrm{~V} / 220 \mathrm{~V}$ applications. IEEE Transactions on Power Electronics, 27(12): 4821-4826.

Lazzarin TB, Moccelini MP, and Barbi I (2013). Direct buck-type AC-AC converter based on switched-capacitor. In the Brazilian Power Electronics Conference, IEEE: 230-235. https://doi.org/10.1109/COBEP.2013.6785120

Terada S, Oota I, Eguchi K, and Ueno F (2004). A ring type switched-capacitor (SC) programmable converter with DC or AC input/DC or AC output. In The $47^{\text {th }}$ Midwest Conference on Circuits and Systems, IEEE: 1: 29-32. https://doi.org/10.1109/MWSCAS.2004.1353889

Ueno F, Inoue T, Oota I, and Harada I (1993). Realization of a switched-capacitor AC-AC converter. In the $11^{\text {th }}$ European Conference on Circuit Theory and Design, Davos, Switzerland: 1177-1180. Available online at: http://ci.nii.ac.jp/ naid/10000076692/

You J and Hui C (2014). A novel switched-capacitor AC-AC converter with a ratio of $1 / 4$. In the $17^{\text {th }}$ International Conference on Electrical Machines and Systems, IEEE: 32053207. https://doi.org/10.1109/ICEMS.2014.7014044 